\title{
Death of an infant after contacting a telephone triage call centre: is telephone triage really safe?
}

\author{
Antony Nocera \\ Emergency Department, Dubbo Base Hospital, Dubbo, New South Wales, Australia
}

Correspondence to Antony Nocera, emedtonynoce@optusnet.com.au

\section{Summary}

The death of a previously well 13-month-old infant approximately $5 \mathrm{~h}$ after his mother contacted the Queensland Nurse led telephone triage call centre '13Health' for advice is the first Australian casualty of telephone triage. Experience from this case and another 'near miss' incident Australia highlight the potential of this model of care to harm patients using the service when it attempts to provide health advice compared with health information.

\section{BACKGROUND}

Telephone triage centres having been introduced in the UK and Australia without any formal evaluation. This case adds to similar cases in the UK to show that telephone triage is potentially dangerous in those patients with emergency medical conditions. I hope that this paper will stimulate a proper evaluation of these services as the fact that this death occurred in Australia in addition to those in the UK highlight the problem lies with the model of care.

\section{CASE PRESENTATION}

The mother of a previously well 13-month-old male infant had a recent chickenpox infection and took her son to his general practitioner (GP) on 9 October 2006 where he received an immunisation against chickenpox. On the night of Saturday 14 October 2006 the infant developed fever of $38.5^{\circ} \mathrm{C}$ and mother noted the child did not want to eat, but was drinking, and had a runny nose. The mother, based in suburban Brisbane, called '13Health' for assistance on the morning of Sunday 15 October 2006 as she was concerned about the continuing fever and child's demeanour.

- 09:32 Mother calls 13Health

- After basic demographic information was obtained the infant's mother was asked a total of 25 complaint specific questions from a 55 question 'Fever-Toddler' protocol (figure 1)

- 09:47 13Health Telephone triage consultation terminated with mother being advised to see her GP in the morning

- 10:00 Child placed in cot

- 11:30 Child walks into lounge room

- 12:00 Child put back to bed

- 14:39 Child found in cot not moving or breathing. Queensland Ambulance Service called

- 14:42 Queensland Ambulance Service on scene

- 15:15 Queensland Police notified of the death

At autopsy there was patchy congestion and haemorrhage of the lower lobes of both lungs being more prominent in the right lung. Postmortem pulmonary cultures revealed the presence of adenovirus and Streptococcus pneumoniae. There was no evidence of the spread of these organisms in the rest of the body. There was no evidence of chickenpox pneumonia.

\section{DISCUSSION}

The death of a previously well 13-month-old infant in 2006 shortly after his mother contacted the Queensland nurse led telephone triage call centre ' 13 Health' for advice is the first Australian death associated with telephone triage. This death was followed by a 'near miss incident' in 2007 in another Australian State. In this incident an adult female contacted the service for advice because of fever, myalgia and arthralgia. She was advised to take paracetamol to lower her temperature and go to bed. She called the service again because of increasing pain and was told to take a bath with two tablespoons of bicarbonate of soda for $20 \mathrm{~min}$. After the bath she called an ambulance and was transported to hospital where she was successfully treated for her meningococcal infection. ${ }^{1}$

Australia is in the process of developing a national telephone triage call centre network by July 2011. This network is based upon the British NHS Direct nurse led telephone triage call centres which were established in 1998. The available literature on telephone triage call centres is confusing as there are several models of care that are either described, or indexed in the medical literature, as 'telephone triage'. These include nurse led telephone triage call centres using computer prompted protocols, GP supervised nurse staffed call centres and afterhours call centres for either individual or groups of medical practitioners.

In addition there is no distinction made between giving health information by telephone, versus telephone advice as to whether or not to seek medical attention. The risks associated these separate functions are not equivalent as demonstrated by this case. Telephone triage assessments can be further hindered by the normal variations in English language skills and syntax in the community which can impact upon how individual's expresses their symptoms, and their responses to medical questioning. Several life threatening emergency medical conditions in 

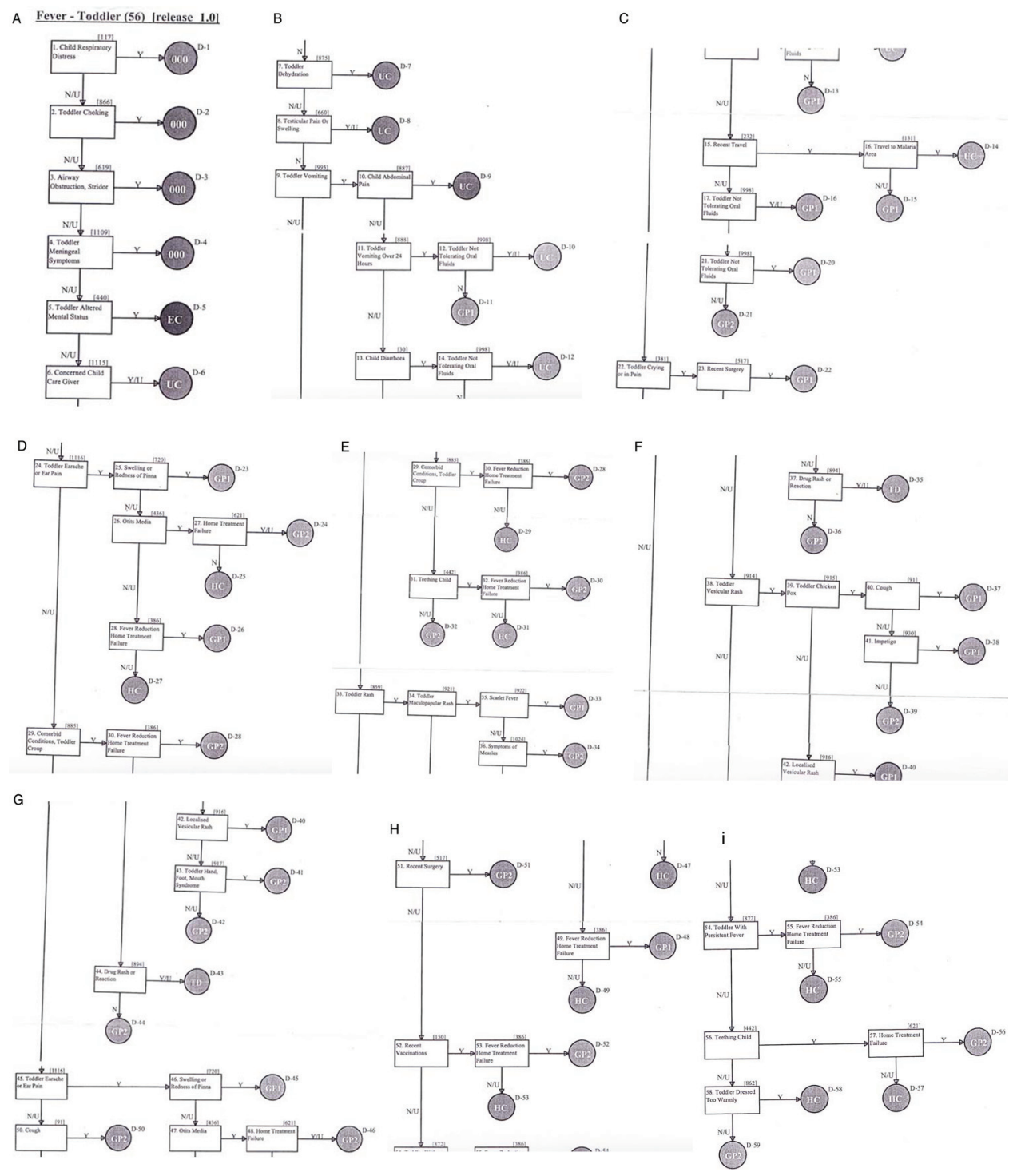

Figure 1 Fever-toddler protocol as tendered in to the Queensland Coroner.

adults and children may initially have vague or non-specific symptoms. ${ }^{2}$

Telephone triage ignores the important role of visual cues in assigning a triage priority to a patient's symptoms in the emergency department. The correlation between nurses performing telephone versus in-person triage in noncritically ill patients presenting to the emergency department is only $43.1 \% .^{3}$ Even when triage certified nurses used structured triage protocols combined with knowledge of a patient's vital signs the correlation between telephone versus in-person triage was still only $48.8 \%$. $^{3}$

All available evidence indicates that telephone triage call centres do not decrease, and may even increase emergency department presentations ${ }^{4}$ in the UK and New Zealand. ${ }^{5}$

Experience from Australia is that up to $36.4 \%$ of calls are advised to see a doctor immediately with $9.1 \%$ requiring emergency ambulance transport. ${ }^{6}$ In addition $5 \%$ of callers ignore the call centre advice and subsequently present to the emergency department despite being advised otherwise. ${ }^{7}$ Problems with telephone triage can arise because patients can be confused about when they need to call for an ambulance directly rather than call a telephone triage call centre. ${ }^{8}$ Call centre screening introduces avoidable delays for individuals with potentially time critical emergencies which would not exist if patients called for an ambulance directly. ${ }^{9}$ Delays in the treatment of time critical emergency can result in either potentially preventable deaths or unnecessarily complicate their medical treatment and hospital stay. ${ }^{29}$

Telephone triage call centres are beneficial by providing a single point of contact for health information for members of the community $24 \mathrm{~h}$ a day. In addition telephone triage call centres can help direct members of the community to a GP afterhours and allow GPs manage their afterhour's workload. For those hospitals that do not prohibit staff providing telephone advice, telephone triage call centres can provide a standardised advice service that relieves emergency department staff in these hospitals. Improved indexing of medical literature on telephone triage call centres is required to be able to ascertain what impacts telephone triage call centres have on patient outcomes, which has to be an integral consideration of any evaluation of these services. 


\section{Learning points}

- It is dangerous to base health policy on the assumption that patients seeking GP services as being the same as those patients with non-specific symptoms concerned that they may have an emergency medical condition. While there is overlap between these two groups of patients are not identical.

- Telephone triage assessments cannot exclude life threatening illness in callers concerned that they may have an emergency medical condition.

- Further research is needed to evaluate the impact of telephone triage call centres on the health outcomes of people using the service.

Competing interests None.

Patient consent Not obtained.

\section{REFERENCES}

1. McArthur G. Nurse on call outcry. Herald Sun, 18 January 2007.

2. Farrer K, Rye P, Murdoch L, et al. NHS direct. Clinicians must be able to provide feedback and evaluate advice given. BMJ 2000;321:446.

3. Salk ED, Schriger DL, Hubbell KA, et al. Effect of visual cues, vital signs, and protocols on triage: a prospective randomized crossover trial. Ann Emerg Med 1998;32:655-64.

4. Bunn F, Byrne G, Kendall S. Telephone consultation and triage: effects on healthcare use and patient satisfaction. Cochrane Database Syst Rev 2004;4:CD004180.

5. Graber DJ, Ardagh MW, O'Donovan P, et al. A telephone advice line does not decrease the number of presentations to Christchurch Emergency Department, but does decrease the number of phone callers seeking advice. N Z Med J 2003;116:U495.

6. Turner VF, Bentley PJ, Hodgson SA, et al. Telephone triage in Western Australia. Med J Aust 2002;176:100-3.

7. Sprivulis $\mathbf{P}$, Carey M, Rouse I. Compliance with advice and appropriateness of emergency presentation following contact with the HealthDirect telephone triage service. Emerg Med Australas 2004;16:35-40.

8. Hildebrandt DE, Westfall JM, Smith PC. After-hours telephone triage affects patient safety. J Fam Pract 2003;52:222-7.

9. Car J, Koshy E, Bell D, et al. Telephone triage in out of hours call centres. BMJ 2008;337:a1167.

This pdf has been created automatically from the final edited text and images.

Copyright 2010 BMJ Publishing Group. All rights reserved. For permission to reuse any of this content visit http://group.bmj.com/group/rights-licensing/permissions.

BMJ Case Report Fellows may re-use this article for personal use and teaching without any further permission.

Please cite this article as follows (you will need to access the article online to obtain the date of publication).

Nocera A. Death of an infant after contacting a telephone triage call centre: is telephone triage really safe?. BMJ Case Reports 2010;10.1136/bcr.08.2009.2144, date of publication

Become a Fellow of BMJ Case Reports today and you can:

- Submit as many cases as you like

- Enjoy fast sympathetic peer review and rapid publication of accepted articles

- Access all the published articles

- Re-use any of the published material for personal use and teaching without further permission

For information on Institutional Fellowships contact consortiasales@bmjgroup.com

Visit casereports.bmj.com for more articles like this and to become a Fellow 